ScIDice

\section{Preference Of Acrylic Crowns In Permanent Teeth Of Paediatric Patients In Dental Teaching Hospitals}

ISSN: $2377-8075$

Research Article

Prerna Jain ${ }^{1}$, Mebin George Mathew ${ }^{2 *}$, Manish Ranjan ${ }^{3}$

${ }^{1}$ Undergraduate Student, Saveetha Dental College and hospitals Saveetha University of Medical And Technical Science (SIMATS) Saveetha University. Chennai-600077, India.

${ }^{2}$ Senior Lecturer, Department of Paediatric and Preventive Dentistry, Saveetha Dental College and Hospitals Saveetha University of Medical And Technical Science(SIMATS) Saveetha University. Chennai-600077, India.

${ }^{3}$ Associate Professor, Department of Conservative and Endodontic Dentistry, Saveetha Dental College and Hospitals, Saveetha Institute of Medical and Technical Sciences,Saveetha University, Chennai 600 077, Tamil Nadu, India.

\title{
Abstract
}

Aim: To assess the preference of acrylic crowns in permanent teeth of paediatric patients in dental teaching hospitals.

Materials and Methods: In this retrospective study, data was collected from the records of patients who visited the Department of Pedodontics and Preventive Dentistry at Saveetha Dental College from June 2019 to March 2020. 73 children who fulfilled the criteria were included in the study. Descriptive statistics and chi square test was done.

Results: The analysis showed that the boys required acrylic crowns more than girls. The most common age group that required acrylic crowns was 11-15 years and the most common tooth was maxillary permanent central incisors. This study shows positive correlation and is not significant since $\mathrm{p}=0.706$.

Conclusion: Within the limits of the study, acrylic crowns were more commonly given to boys. Permanent maxillary central incisors were the teeth that received the maximum number of acrylic crowns.

Clinical Significance: Acrylic crowns can be used for permanent teeth that have received endodontic therapy.

Keywords: Acrylic Crowns; Adolescents; Age; Esthetic Management; Permanent Teeth.

\section{Introduction}

Aesthetics is a primary consideration for patients seeking orthodontic, prosthodontic and restorative treatment [1, 2]. Interest in dental aesthetics has increased rapidly during the last few decades among patients and dentists, and the creation of a natural dental appearance has become an important task in the fields of dentistry [3]. Numerous factors are related to dental aesthetics such as colour, shape and position of teeth and shape of dental arch. These factors are affected by individual preferences, cultural and sociodemographic factors. Perception of tooth appearance can be influenced by age, gender and education levels $[4,5]$.

Grossly destructed anteriors and compromised esthetics are very commonly seen in children of young age. Even though the de- ciduous dentition is temporary dentition, it has a definitive role in oral cavity until it's exfoliation [6]. Maxillary anterior teeth dominate the physical appearance, and their structural loss affects not only esthetics but also leads to compromised mastication, poor phonetics, development of aberrant oral habits, neuromuscular imbalance, and difficulty in social and psychological adjustment of the child [7]. In the modern, civilized world, well-contoured and well-aligned white teeth are attractive but are also indicative of nutritional health, self-esteem, hygienic pride, and economic status [8]. The main problem facing the clinician while performing esthetic restorations in children is the small size of teeth, proximity of the pulp to the tooth surface, relatively thin enamel, and surface area for bonding a restoration, and the behaviour of the child [9]. Numerous treatment approaches have been proposed to address the esthetics and retention of restorations in

\section{*Corresponding Author}

Mebin George Mathew,

Senior Lecturer, Department of Paediatric and Preventive Dentistry, Saveetha Dental College and Hospitals Saveetha University of Medical And Technical Science(SIMATS) Saveetha University. Chennai-600077, India.

Tel: :+91-8951748659

Email ID: mebingeorgem.sdc@saveetha.com

Received: December 02, 2020

Accepted: January 21, 2021

Published: February 27, 2021

Citation: Prerna Jain, Mebin George Mathew, Manish Ranjan. Preference Of Acrylic Crowns In Permanent Teeth Of Paediatric Patients In Dental Teaching Hospitals. Int J Dentistry Oral Sci. 2021;08(02):1801-1804. doi: http://dx.doi.org/10.19070/2377-8075-21000357

Copyright: Mebin George Mathew 2021. This is an open-access article distributed under the terms of the Creative Commons Attribution License, which permits unrestricted use, distribution and reproduction in any medium, provided the original author and source are credited. 
paediatric patients like stainless steel crowns, strip crowns, and other prefabricated crowns $[10,11]$ but the best option available apart from the routine tooth coloured restorations is the heat cure acrylic crown.

Pediatric Crowns are dental crowns used for restoring lost or damaged or decayed teeth of children. These crowns encircle the damaged teeth completely and are made of different materials such as ceramic, steel and acrylic $[12,13]$. Acrylic crowns are made of polycarbonate resin shells with micro-glass fibers and have been temporarily used to restore children's teeth. Advantages of acrylic crowns include slightly translucent, tooth colored and easy to manipulate. They are contraindicated in cases like bruxism, deep bite and excessive abrasion $[14,15]$.

Children's teeth play a key role in dental development. They are important as they not only hold space for permanent teeth, but they are essential for chewing, biting, speaking and appearance. In addition, they guide the permanent teeth into place [16]. Due to this, missing primary teeth or who prematurely lose primary teeth may require restorative management treatment or space maintainer to hold the natural space open [17]. Without the care, the teeth can tilt toward the empty space and cause permanent teeth to come in crooked or rotated form. The child establishes oral hygiene habits with the primary teeth, so they play a critical role in how they treat permanent teeth [18]. Permanent teeth management is often considered of utmost importance when compared to that of primary teeth as they determine the future dentition of a child. The dental health of children is compromised as it depends on the knowledge, awareness, and attitude of the parents $[19,20]$.

This study is indicated to assess the prevalence of acrylic crowns as a treatment modality for aesthetic management in permanent teeth of paediatric patients. It will fulfil any shortcomings or deficiency in assessment and understanding of acrylic crowns as a choice of treatment in paediatric restorative management.

The aim of the study is to assess the usage of acrylic crowns in permanent teeth of paediatric patients in dental teaching hospital with respect to age and gender status.

\section{Materials and Methods}

The present study was undertaken after receiving ethical approval from the Institutional Review Board. Ethical approval number : SDC/SIHEC/2020/DIASDATA/0619-0320. Children who visited Saveetha dental college and hospitals, Chennai were evaluated between June 2019-March 2020 and had received acrylic crowns were included in the study. All primary teeth and other crowns were considered as the exclusion criteria. To minimise sampling bias, all available data was included with a sorting process of removing double entries.

The data was retrospectively obtained from the treatment records of patients who visited the Department of Pedodontics and Preventive Dentistry of Saveetha Dental College from June 2019 to March 2020. A total of 73 children between the age group 8-17 years who had undergone treatment of acrylic crowns in permanent teeth were included in the study. Data was verified by one external reviewer. The data was then exported to SPSS and the variables were identified.

Chi square test was performed on the data using SPSS version 20 software. Type of analysis done was correlation analysis.

\section{Results and Discussion}

The data collected from the patient management software was tabulated in SPSS and the descriptive analysis was obtained.

Out of a total of 73 children , 70\% are boys and 30\% are girls within the age group of 8-17 years were present in the study analysis. Of which, 7 boys in the age group of $8-10$ years, 27 boys in 11-15 years and 17 boys in 16-18 years old were present. In the female category, 3 were present in the 8-10 years age group, 10 girls in 11-15 years and 9 girls above 16 years old were present (Figure 1). Figure 1 represents the age gender distribution of children in the study. Figure 2 represents the frequency distribution of teeth that received acrylic crowns.

Chi square test was done between age and gender of the population. Results showed positive correlation and are not significant since $p=0.706$. Most common teeth that were affected were maxillary permanent right and left central incisor. (Figure 2)

\section{Discussion}

In the past, the only option for management of trauma to the permanent anterior teeth would have been to extract the affected

Figure 1. Age Distribution of Children in the study.

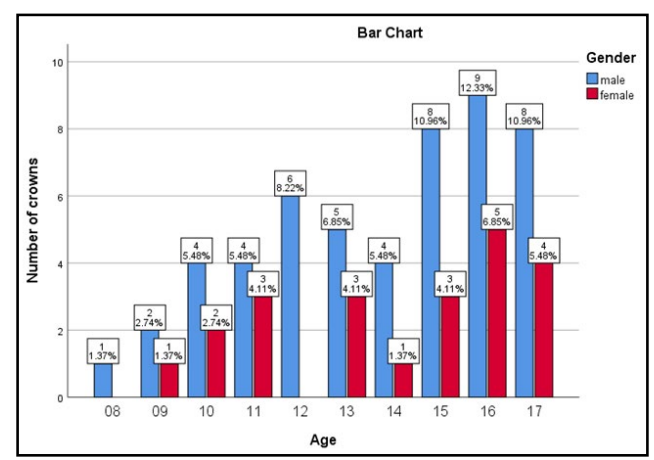

This graph represents the correlation age and gender of children who received acrylic crowns where blue colour denotes boys and red colour denotes girls. X axis denotes the age and $\mathrm{Y}$ axis denotes the number of children, shows that the maximum number of crowns were given to boys aged 16 years ( 9 crowns, $12.33 \%$ ) followed by boys aged 15 and 17 years (8 crowns 10.96\%). Pearson's chi square value : 4.359, p value :0.706, hence statistically not significant (Chi square analysis) 
Figure 2. Shows Frequency distribution of teeth that received acrylic crowns.

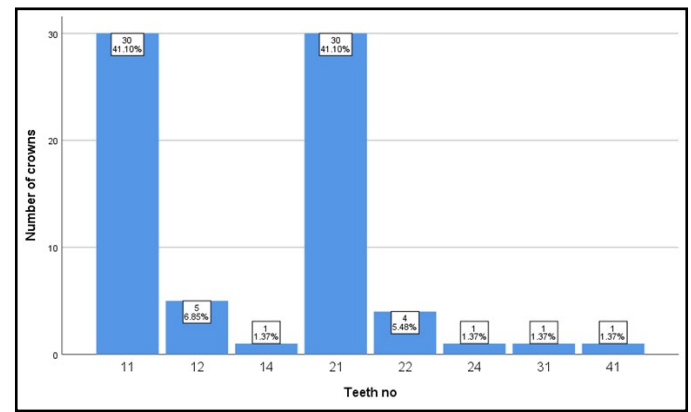

$\mathrm{X}$ axis denotes tooth number and y axis denotes number of crowns. Out of the 73 children in the study, 30 children received acrylic crowns on $11(41.10 \%)$ and 2 (41.10\%). 5 children received crowns on $12(6.85 \%), 4$ children received crowns on $22(5.48 \%) .1$ crown was placed on $14(1.37 \%), 24(1.37 \%), 31(1.37 \%)$ and 41 $(1.37 \%)$. The teeth that received the maximum acrylic crowns are right and left permanent central incisors.

teeth and replace them with prosthetic substitutes. However, the availability of natural crowns and roots would allow the use of biologic restorations to preserve the integrity of a patient's natural dentition [21]. Esthetic restorations in permanent teeth have been a great concern and challenging task for most of the clinicians. Which is why acrylic crowns are used in permanent anteriors of paediatric patients since these crowns are custom made, have an esthetic appearance, better retention and stability than compared to the other options. The restorative treatment of acrylic crown placement gives the dentist satisfaction of knowing that they have restored the smile and self confidence of a growing child [22]. In many cases of restoration of permanent maxillary incisors, successful outcome depends on the ability of the practitioner's precise decision about restorative method and material selections. Most cases are observed in children with severe traumatic injuries or extensive caries. It is a commonly faced problem in dental clinics. Some authors have reported successful outcomes of the restoration of permanent maxillary incisors of severely destroyed cases by trauma or caries. It may enhance the clinician's ability and materials to restorative anterior teeth compared to the past [23].

However, the restoration of permanent anterior teeth presents complicated aesthetic and retention problems to the clinician. The choice of the most appropriate restoration for anterior teeth is often a difficult decision. Numerous clinical and technical factors play an important role in selecting the treatment option that best suits the patient and the restorative team [24]. Experienced clinicians have developed decision processes that are often more complex than that may seem. Less experienced professionals may find difficulties making treatment decisions because of the widely varied restorative materials available and often numerous similar products offered by different manufacturers [25].

Very few studies were present related to the usage of acrylic crowns as a treatment modality for aesthetic management in permanent teeth for paediatric patients [26].

A study conducted by Deshpande A et al., [27] concluded that the children involved in their study were 8-16 year olds. This was in acceptance with the present study where the common age group is 16 years old. The reason for this similarity may be the fact that this would be the common age group for injuries affecting anterior teeth especially maxillary central incisors.

Sakai VT et al., [28] reported that most of the children involved in this study were boys which was in acceptance with the present study. The reason for this similarity in the studies might be that boys are more prone to injuries when compared to girls.

A study conducted by Jain $\mathrm{M}$ et al., [29] concluded that the most common teeth involved in this study were primary teeth. This was in contradiction with the present study which reported that permanent right central incisor is the most commonly affected tooth. The reason for this difference can be due to traumatic injuries commonly affecting anterior teeth.

Early loss of the anterior permanent teeth may lead to psychological disturbances and affect the child's self-esteem and socialization during the important phase of development. Teeth lost in the anterior region infrequently require space maintenance, but demand rehabilitation from a psychological point of view, as many a time, children suffer without being vocal about it [30].

Present Study had few limitations such as a small sample size from a single centre. However the long term follow up of these cases will allow us to see the success rates of acrylic crowns in pediatric patients.

\section{Conclusion}

The usage of acrylic crowns as a treatment modality for aesthetic management in permanent teeth for paediatric patients is considered as an excellent option to restore a child's smile and confidence. Within the limits of the study, acrylic crowns were more commonly given to boys. Permanent maxillary central incisors were the teeth that received the maximum number of acrylic crowns.

\section{Clinical Significance}

Acrylic crowns can be used for permanent teeth that have received endodontic therapy.

\section{Acknowledgement}

We would like to acknowledge the Department of Research and IT, Saveetha Dental College and Hospitals, Saveetha Institute Medical and Technical Sciences for their help during the study.

\section{References}

[1]. Hasanreisoglu U, Berksun S, Aras K, Arslan I. An analysis of maxillary 
anterior teeth: facial and dental proportions. J Prosthet Dent . 2005 Dec 1;94(6):530-8.

[2]. Perception of orthodontic treatment needed in children and adolescents [Internet]. Paperpile. [cited 2020 Jun 3]. Available from: https://paperpile.com/ app/p/72ef4837-eelf-0a6a-8e12-2ef147beb200

[3]. Carlsson GE, Johansson A, Johansson AK, Ordell S, Ekbäck G, Unell L. Attitudes toward dental appearance in 50- and 60-Year-old subjects living in Sweden. J Esthet Restor Dent. 2008;20(1):46-55; discussion 56.Pubmed PMID: 18237340.

[4]. Lombardi RE. The principles of visual perception and their clinical application to denture esthetics. J Prosthet Dent. 1973 Apr;29(4):358-82.Pubmed PMID: 4570911.

[5]. Marunick MT, Chamberlain BB, Robinson CA. Denture aesthetics: an evaluation of laymen's preferences. J Oral Rehabil. 1983 Sep;10(5):399-406. Pubmed PMID: 6355414.

[6]. Somasundaram S, Ravi K, Rajapandian K, Gurunathan D. Fluoride Content of Bottled Drinking Water in Chennai, Tamilnadu. J Clin Diagn Res. 2015 Oct;9(10):ZC32-4.Pubmed PMID: 26557612.

[7]. Jathar P, Panse A, Desai AR. Acrylic crowns for esthetic rehabilitation of primary teeth. Int. J. Pedod. Rehabil. 2018 Jan 1;3(1):42.

[8]. Arens D. The role of bleaching in esthetics. Dent. Clin. N. Am. 1989 Apr 1;33(2):319-36.

[9]. Venkataraghavan K, Chan J, Karthik S. Polycarbonate crowns for primary teeth revisited: restorative options, technique and case reports. J Indian Soc Pedod Prev Dent. 2014 Apr-Jun;32(2):156-9.Pubmed PMID: 24739917.

[10]. Hartmann CR. The open-face stainless steel crown: an esthetic technique. J. Dent. Child.. 1983;50:31-3.

[11]. Pollard MA, Curzon JA, Fenlon WL. Restoration of decayed primary incisors using strip crowns. Dent. Update. 1991 May 1;18(4):150-2.

[12]. Kedo-S Paediatric Rotary Files for Root Canal Preparation in Primary Teeth - Case Report [Internet]. Paperpile. [cited 2020 Jun 3]. Available from: https://paperpile.com/app/p/ec3087e5-92e6-0ed1-b0a4-302b2ee4ddfe

[13]. Govindaraju L, Jeevanandan G, Subramanian EMG. Comparison of quality of obturation and instrumentation time using hand files and two rotary file systems in primary molars: A single-blinded randomized controlled trial. Eur J Dent. 2017 Jul-Sep;11(3):376-379.Pubmed PMID: 28932150.

[14]. Govindaraju L, Jeevanandan G, Subramanian EM. Knowledge and practice of rotary instrumentation in primary teeth among indian dentists: A questionnaire survey. J Int Oral Health. 2017 Mar 1;9(2):45.

[15]. Jeevanandan G, Govindaraju L. Clinical comparison of Kedo-S paediatric rotary files vs manual instrumentation for root canal preparation in primary molars: a double blinded randomised clinical trial. Eur Arch Paediatr Dent. 2018 Aug;19(4):273-278.Pubmed PMID: 30003514.

[16]. A importância da proporção largura/comprimento em dentes permanentes superiores anteriores na reabilitação estética [Internet]. Paperpile. [cited 2020 Jun 3]. Available from: https://paperpile.com/app/p/6e1c3893-ba32- 0d74-a380-2b430cb146c3

[17]. Govindaraju L, Jeevanandan G, Subramanian E. Clinical Evaluation of Quality of Obturation and Instrumentation Time using Two Modified Rotary File Systems with Manual Instrumentation in Primary Teeth. J Clin Diagn Res. 2017 Sep;11(9):ZC55-ZC58.Pubmed PMID: 29207834.

[18]. Vittoba Setty J, Srinivasan I. Knowledge and Awareness of Primary Teeth and Their Importance among Parents in Bengaluru City, India. Int J Clin Pediatr Dent. 2016 Jan-Mar;9(1):56-61.Pubmed PMID: 27274157.

[19]. Ravikumar D, Jeevanandan G, Subramanian EM. Evaluation of knowledge among general dentists in treatment of traumatic injuries in primary teeth: A cross-sectional questionnaire study. Eur J Dent. 2017 Apr;11(02):232-7.

[20]. Panchal V, Jeevanandan G, Subramanian E. Comparison of instrumentation time and obturation quality between hand $\mathrm{K}$-file, $\mathrm{H}$-files, and rotary Kedo-S in root canal treatment of primary teeth: A randomized controlled trial. J Indian Soc Pedod Prev Dent. 2019 Jan-Mar;37(1):75-79.Pubmed PMID: 30804311.

[21]. Ramakrishnan M, Bhurki M. Fluoride, Fluoridated Toothpaste Efficacy And Its Safety In Children-Review. Int. J. Pharm. Sci. Res. 2018 Oct $1 ; 10(04): 109-14$

[22]. Rosenstiel SF, Land MF, Fujimoto J. Contemporary fixed prosthodontics. 2001.

[23]. Packiri S, Gurunathan D, Selvarasu K. Management of paediatric oral ranula: a systematic review. J Clin Diagn Res. 2017 Sep;11(9):ZE06-9.

[24]. Gurunathan D, Shanmugaavel AK. Dental neglect among children in Chennai. J Indian Soc Pedod Prev Dent. 2016 Oct 1;34(4):364-9.

[25]. Govindaraju L, Gurunathan D. Effectiveness of Chewable Tooth Brush in Children-A Prospective Clinical Study. J Clin Diagn Res. 2017 Mar;11(3):ZC31-ZC34.Pubmed PMID: 28511505.

[26]. Subramanyam D, Gurunathan D, Gaayathri R, Vishnu Priya V. Comparative evaluation of salivary malondialdehyde levels as a marker of lipid peroxidation in early childhood caries. Eur J Dent. 2018 Jan-Mar;12(1):67-70. Pubmed PMID: 29657527; PMCID: PMC5883478.

[27]. Christabel SL, Gurunathan D. Prevalence of type of frenal attachment and morphology of frenum in children, Chennai, Tamil Nadu. World J Dent. 2015 Oct;6(4):203-7.

[28]. Sakai VT, Anzai A, Silva SM, Santos CF, Machado MA. Predictable esthetic treatment of fractured anterior teeth: a clinical report. Dent Traumatol. 2007 Dec;23(6):371-5.

[29]. Jain M, Singla S, Bhushan B, Kumar S, Bhushan A. Esthetic rehabilitation of anterior primary teeth using polyethylene fiber with two different approaches. J Indian Soc Pedod Prev Dent. 2011 Oct-Dec;29(4):327-32. Pubmed PMID: 22016319.

[30]. Lakshmanan L, Mani G, Jeevanandan G. Assessing the quality of obturation and instrumentation time using Kedo-S files, Reciprocating files and Hand K-files. Braz. Dent. Sci. 2020;23. 